\title{
Exploring 6-Azaindole and 7-Azaindole Rings for Developing Cannabinoid Receptor 1 Allosteric Modulators
}

\author{
Sri Sujana Immadi, ${ }^{1}$ Rachel Dopart, ${ }^{2}$ Zhixing Wu, ${ }^{1}$ Boqiao Fu, ${ }^{1}$ Debra A. Kendall, ${ }^{2}$ and Dai Lu, ${ }^{1, *}$
}

\begin{abstract}
Introduction and Objective: Org27569 is a prototypical allosteric modulator of the cannabinoid receptor 1 $\left(\mathrm{CB}_{1}\right)$. It belongs to the indole-2-carboxamide scaffold and has been intensively investigated in pharmacology and in structure-activity relationship (SAR) studies. Although azaindoles are rare in natural products and differ only by the presence of an extra ring nitrogen, they were demonstrated as valuable bioisosteres in many pharmacologically important molecules. To extend the SAR investigation of the indole-2-carboxamide class of $\mathrm{CB}_{1}$ allosteric modulators, azaindole (pyrrolopyridine) rings were used to replace the indole ring of Org27569 analogs to explore the potential of azaindole-2-carboxamides as $\mathrm{CB}_{1}$ allosteric modulators. Using 6- and 7-azaindole in lieu of the indole moiety within this class of $\mathrm{CB}_{1}$ allosteric modulators indeed improved the aqueous solubility. Materials and Methods: We synthesized 6- and 7-azaindole-2-carboxamides and their indole-2-carboxamide counterparts. The molecules were evaluated by $\left[{ }^{3} \mathrm{H}\right] \mathrm{CP} 55,940$ binding and $\left[{ }^{35} \mathrm{~S}\right] \mathrm{GTP} \gamma \mathrm{S}$ binding assays for their allosteric modulation of the $\mathrm{CB}_{1}$ receptor.

Results: The 7-azaindole-2-carboxamides lost the ability to bind to the $\mathrm{CB}_{1}$ receptor. The 6-azaindole-2carboxamides (e.g., $3 \mathrm{c}$ and $3 \mathrm{~d}$ ) showed markedly reduced binding affinities to the $\mathrm{CB}_{1}$ receptor in comparison with their indole-2-carboxamide counterparts. However, they behaved similarly as indole-2-carboxamides in potentiating the orthosteric agonist binding and inhibiting the orthosteric agonist-induced G-protein coupling. The results indicated that some azaindole scaffolds (e.g., 6-azaindole) are worth further exploration, whereas the 7-azaindole ring is not a viable bioisostere of the indole ring in the Org27569 class of $\mathrm{CB}_{1}$ allosteric modulators.
\end{abstract}

Keywords: allosteric modulators; azaindole; bioisostere; cannabinoid; $\mathrm{CB}_{1}$ receptor

\section{Introduction}

The cannabinoid receptor $1\left(\mathrm{CB}_{1}\right)$ is a G-proteincoupled receptor and has been recognized as a promising target for the treatment of many disorders, including pain, inflammation, metabolic syndromes, and neurodegenerative diseases. ${ }^{1}$ However, the $\mathrm{CB}_{1}$ receptor has been challenging as a druggable target because of central nervous system side effects associated with drug candidates that bind to the orthosteric site where the endogenous cannabinoids bind. Therefore, recent efforts have fo- cused on developing allosteric modulators that target $\mathrm{CB}_{1}$ at sites topographically distinct from the orthosteric sites. ${ }^{2}$ Several small molecules have been revealed as $\mathrm{CB}_{1}$ allosteric modulators over the last 10 years. $^{2-4}$

Org27569 is an indole-2-carboxamide and a prototypical $\mathrm{CB}_{1}$ allosteric modulator that has been intensively investigated. ${ }^{5-7}$ Following its discovery, several structure-activity relationship studies have addressed the key requirements to maintain or improve allosteric modulation effects. ${ }^{8}$ Most of the structural optimization

\footnotetext{
${ }^{1}$ Department of Pharmaceutical Sciences, Rangel College of Pharmacy, Health Science Center, Texas A\&M University, Kingsville, Texas.

${ }^{2}$ Department of Pharmaceutical Sciences, University of Connecticut, Storrs, Connecticut.

*Address correspondence to: Dai Lu, PhD, Rangel College of Pharmacy, Health Science Center, Texas A\&M University, 1010 West Avenue B, Kingsville, TX 78363, E-mail: dlu@tamhsc.edu
}

(C) Sri Sujana Immadi et al. 2018; Published by Mary Ann Liebert, Inc. This Open Access article is distributed under the terms of the Creative Commons License (http://creativecommons.org/licenses/by/4.0), which permits unrestricted use, distribution, and reproduction in any medium, provided the original work is properly cited. 
of Org27569 was based on the indole moiety except two cases, in which benzofuran and benzimidazole rings were used in lieu of the indole ring. The binding affinities of the benzofuran analogs of Org27569 were significantly reduced, although the binding cooperativities with the orthosteric agonist were markedly enhanced. ${ }^{9}$ Similarly, the binding affinities of benzimidazole analogs of Org27569 were abolished, while allosteric modulation on agonist-induced GTP $\gamma S$ binding was maintained. ${ }^{10}$

In recent years, azaindoles (pyrrolopyridine) have gained significant attention as the bioisosteres of the indole ring due to their ability to facilitate pharmaceutical optimization, such as increasing solubility, reducing lipophilicity, enhancing target binding, and improving ADME as well as toxicology properties. ${ }^{11-15}$

The fusion of a pyrimidine ring and a pyrrole ring can provide a pyrrolopyridine structure having four isomers (i.e., 4-, 5-, 6-, and 7-azaindoles). Among them, the 7azaindoles have been demonstrated with luminescent and fluorescent properties, which can render the molecule containing the 7-azaindole moiety with some chromophoric functions. ${ }^{11,12}$ In the synthesis of a group of cannabinoid receptor agonists from the known cannabinoid ligand JWH-018, it was demonstrated that bioisosteric replacement of the indole ring with the azaindole moieties (e.g., 5-, 6-, and 7-azaindoles) substantially improved the physicochemical properties of the resultant compounds. ${ }^{16}$ In addition, bioisosteric replacement of the indole ring with an azaindole moiety can enhance the drug-target in- teraction by formation of an extra hydrogen bond and significantly increase the pharmacological effects. ${ }^{17,18}$

In addition to the frequently used 5-, 6-, and 7azaindoles, the 4-azaindoles also was reported as a viable bioisosteric replacement of indole. ${ }^{19}$ With the goal of increasing aqueous solubility and developing a new scaffold, we designed and synthesized 6-azaindole-2-carboxamides (3c, 3d) and 7-azaindole2-carboxamides $(9 a, 9 b)$ to compare with their indole-2-carboxamide counterparts ( $3 a$ and $3 b$ ) to explore the possibility of developing $\mathrm{CB}_{1}$ allosteric modulators. We used dimethylaminophenyl ethylamine and piperidinylphenyl ethylamine, which have been shown in the previous series of indole-2carboxamides to improve function ${ }^{8,20,21}$ and to synthesize the target 6-and 7-azaindole-2-carboxamides shown in Figure 1C. The aqueous solubility of some synthesized compounds were assessed by measurement of their thermodynamic solubility because kinetic solubility data frequently overestimates solubility compared to thermodynamic solubility. ${ }^{22}$

\section{Materials and Methods}

Chemistry

The synthesis of reference indole-2-carboxamides $3 \mathrm{a}$ and $3 \mathrm{~b}$ was carried out by coupling of commercially available 5-chloro-indole-2-carboxylic acid with commercially available 4-(2-aminoethyl)- $N, N$-dimethylaniline (2a) and 2-(4-(piperidin-1-yl)phenyl)ethanamine (2b), respectively,

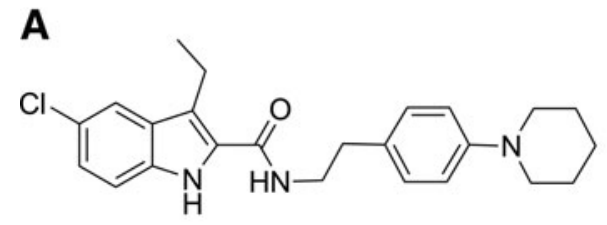

B

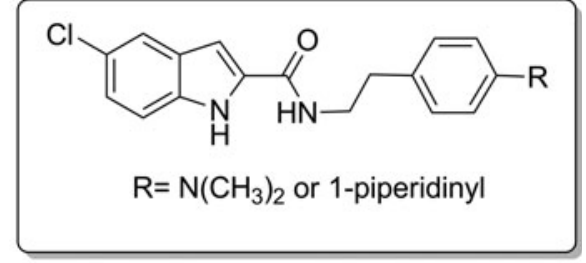

C

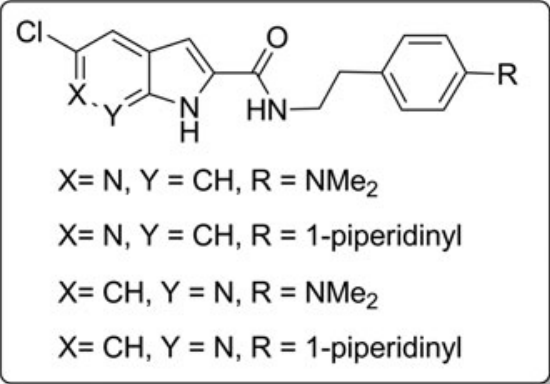

FIG. 1. Prototypical $\mathrm{CB}_{1}$ allosteric modulator $\operatorname{Org} 27569$ (A), referenced indole-2-carboxamide analogs of Org27569 (B), and designed 6- and 7-azaindole-2-carboxamides (C). $\mathrm{CB}_{1}$, cannabinoid receptor 1. 
through the catalysis of 4-(4,6-Dimethoxy-1,3,5triazin-2-yl)-4-methylmorpholinium chloride (DMTMM) and $N$-methyl morpholine (NMM) in THF. Similarly, 6-azaindole-2-carboxamides $3 \mathrm{c}$ and $3 \mathrm{~d}$ were synthesized from 5-chloro-6-azaindole-2-carboxylic acid. To synthesize the 7-azaindole-2-carboxamides $9 \mathrm{a}$ and $9 \mathrm{~b}$, the required intermediate methyl 5-chloro-7-azaindole2-carboxylate 7 was obtained through HemetsbergerKnittel indole synthesis with a protocol previously optimized by us. ${ }^{20}$ Hydrolysis of the 7 -azaindole-2carboxylate 7 provided the essential intermediate 5chloro-7-azaindole-2-carboxylic acid 8, which was coupled with $2 \mathrm{a}$ and $2 \mathrm{~b}$, respectively, to yield the target compounds $9 \mathrm{a}$ and $9 \mathrm{~b}$. The experimental details for the synthesis of compounds $3 a-d, 6-8$, and $9 a-$ $9 \mathrm{~b}$ can be found in the Supplementary Data.

Receptor expression and membrane preparation

Human embryonic kidney 293T (HEK293T) cells were grown and seeded in Dulbecco's modified Eagle's medium with $3.5 \mathrm{mg} / \mathrm{mL}$ glucose and $10 \%$ fetal bovine serum at $37^{\circ} \mathrm{C}$ and $5 \%$ carbon dioxide. To express the $\mathrm{CB}_{1}$ receptors, HEK293T cells were seeded at 1,000,000 cells/100$\mathrm{mm}$ plate. The following day, cells were transfected via the calcium phosphate method with $\sim 10 \mu \mathrm{g}$ of human $\mathrm{CB}_{1}$ receptor cloned into pcDNA3.1 ${ }^{23}$ Membranes of the transfected cells were prepared as previously described $21 \mathrm{~h}$ after transfection. ${ }^{24}$

\section{Equilibrium binding assay}

Approximately $3 \mu \mathrm{g}$ of membrane preparation expressing $\mathrm{CB}_{1}$ was incubated with nine concentrations of allosteric modulator $(1 \mathrm{nM}-10 \mu \mathrm{M})$. The radiolabeled tracer $\left[{ }^{3} \mathrm{H}\right] \mathrm{CP} 55,940$ (150.2 Ci/mmol; Perkin Elmer), an orthosteric agonist of $\mathrm{CB}_{1}$, was added at $0.5 \mathrm{nM}$. Nonspecific binding was established by treating with a high concentration of unlabeled CP55,940 (10 $\mu \mathrm{M}$; Tocris). The membranes were incubated at $30^{\circ} \mathrm{C}$ for $60 \mathrm{~min}$, and the reaction was terminated with the addition of $300 \mu \mathrm{L}$ of Tris- $\mathrm{Mg}^{2+}$-EDTA (TME) buffer with $5 \%$ bovine serum albumin (BSA). The mixture was harvested by filtration through a Brandel cell harvester with Whatman GF/C filter paper. Liquid scintillation counting was used to measure radioactivity.

\section{GTP $\gamma$ S binding evaluation}

To assess the impact of $3 \mathrm{c}$ and $3 \mathrm{~d}$ on G-protein coupling of $\mathrm{CB}_{1}$, GTP $\gamma \mathrm{S}$ assays were performed essentially as described previously. ${ }^{20}$ Membranes of $\mathrm{CB}_{1}$ expressing cells were prepared, and $8 \mu \mathrm{g}$ of membrane prepa- ration was incubated with $0.1 \mu \mathrm{M}$ of $\mathrm{CP} 55,940$ plus or minus the allosteric modulator, allosteric modulator alone, or $1 \mu \mathrm{M}$ SR141716A alone, and $0.1 \mathrm{nM}$ $\left[{ }^{35} \mathrm{~S}\right] \mathrm{GTP} \gamma \mathrm{S}$ (1250 Ci/mmol; PerkinElmer Life Sciences, Boston, MA), $10 \mu \mathrm{M}$ GDP (Sigma, St. Louis, MO), and $0.1 \%(\mathrm{w} / \mathrm{v})$ BSA. GTP $\gamma \mathrm{S}$ binding assay buffer $(50 \mathrm{mM}$ Tris-HCl, $\mathrm{pH} 7.4,3 \mathrm{mM} \mathrm{MgCl} 2,0.2 \mathrm{mM}$ EGTA, and $100 \mathrm{mM} \mathrm{NaCl}$ ) was added to $200 \mu \mathrm{L}$. The membranes were incubated for $1 \mathrm{~h}$ at $30^{\circ} \mathrm{C}$. To determine nonspecific binding, $10 \mu \mathrm{M}$ unlabeled GTP $\gamma \mathrm{S}$ (Sigma) was used. To determine basal activity, membrane preparations were treated with vehicle (dimethylsulfoxide or DMSO) alone. Termination of the reaction was achieved through filtration using Whatman GF/C filter papers and washing with cold TME buffer. Bound radioactivity was measured by liquid scintillation counting.

\section{Thermodynamic solubility assessment}

The thermodynamic solubility of selected compounds were tested according to previously reported methods. ${ }^{16,22}$ In brief, stock solution of test compound $(1 \mathrm{mg} / \mathrm{mL})$ in acetonitrile was prepared and then diluted with mobile phase to prepare the calibration standards in the concentration range of $0.1-50 \mu \mathrm{g} / \mathrm{mL}$. Following this, $2 \mathrm{mg}$ of test compound powder was suspended in $2 \mathrm{~mL}$ of phosphate-buffered saline (PBS; $10 \mathrm{mM}$ ) at $\mathrm{pH} 7.4$ and $37^{\circ} \mathrm{C}$. The suspension was stirred at $37^{\circ} \mathrm{C}$ with $800 \mathrm{rpm}$ stirring for $24 \mathrm{~h}$. After completion of the incubation, the saturated suspension was filtered through a syringe polytetrafluoroethylene filter $(0.45 \mu \mathrm{m})$, which has no absorption for the compounds. $200 \mu \mathrm{L}$ of the filtrate was diluted with $800 \mu \mathrm{L}$ acetonitrile immediately to a final volume of $1 \mathrm{~mL}$. Subsequently, $20 \mu \mathrm{L}$ of this solution was used for the highperformance liquid chromatography (HPLC) analysis, which was analyzed on Shimadzu HPLC (LC model: LC20AB, UV/vis detector: SPD20A; Autosampler: SIL-20A HT) with a Phenomenex reverse phase C18 column $(250 \times 3 \mathrm{~mm}$, Luna $5 \mu \mathrm{m} \mathrm{C18} \mathrm{100 \AA ).} \mathrm{The}$ HPLC analysis was carried out by using the mixture of acetonitrile and water $(60: 40 \mathrm{v} / \mathrm{v})$ as the mobile phase with a flow rate of $1 \mathrm{~mL} / \mathrm{min}$. The signals were detected at UV wavelength $254 \mathrm{~nm}$. At this wavelength, each peak's area under the curve was measured and used for the quantitative evaluation.

\section{Results and Discussion}

To synthesize the target azaindole-2-carboxamides, it requires corresponding azaindole-2-carboxylic acids (i.e., $1 \mathrm{~b}$ and 8 ) as the key building blocks (Fig. 2). To 

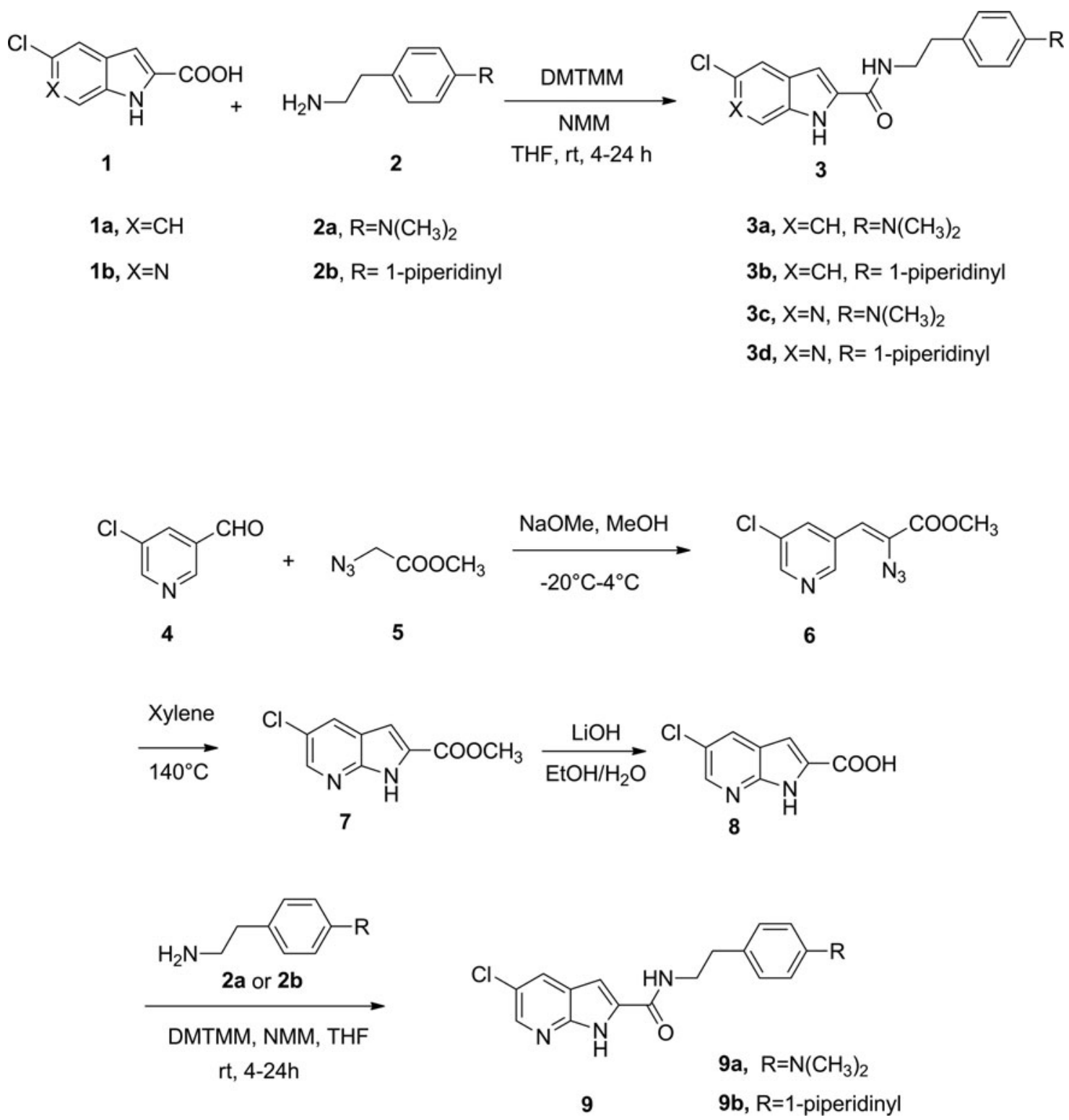

FIG. 2. Synthesis of indole- and azaindole-2-carboxamides. DMTMM, 4-(4,6-Dimethoxy-1,3,5-triazin-2-yl)-4methylmorpholinium chloride; NMM, N-methyl morpholine; THF, tetrahydrofuran.

access these azaindole-2-carboxylic acids, we used the Hemetsberger-Knittel indole synthesis, which involves Knoevenagel condensation between a pyridinecarbaldehyde and the azido acetate $5 .^{20}$ However, the condensation between 5-chloro-pyridine-3-carbaldehyde and the azido acetate 5 failed to provide the desired Knoevenagel product. In this investigation, the 6azaindole-2-carboxylic acid $1 \mathrm{~b}$ was obtained from a commercial source (Achemtek, Worcester, MA). In contrast, the condensation between 2-chloro-pyridine- 4-carbaldehyde (4) and the azido acetate 5 successfully produced the corresponding Knoevenagel product 6, from which the required 7-azaindole-2-carboxylic acid (8) can be easily obtained. Unlike the indole-2caboxylic acids, the coupling of the azaindole-2carboxylic acids $1 \mathrm{~b}$ and 8 with corresponding amines under the catalysis of HOBT or BOP and Hünig's base leads to low yields of the amide $3 c-d$ and $9 a-b$. In contrast, catalyzing the coupling reaction by DMTMM and NMM generally provided the corresponding amides 
in good yields. The synthesized compounds were assessed by equilibrium binding assay, ${ }^{25,26}$ which identifies two important parameters for initial characterization of allostery: $K_{B}$, the equilibrium dissociation constant that defines the affinity of an allosteric modulator for its receptor; and $\alpha$, the cooperativity factor, which defines the magnitude and direction of impact that the allosteric modulator and orthosteric ligand have on each other when both occupy the receptor. At the receptor binding level, when $\alpha$ is $>1$, the ligand is a positive allosteric modulator, whereas when $\alpha$ is $<1$, the ligand is a negative allosteric modulator. Accordingly, when $\alpha$ is equal to 1 , it indicates no allosteric modulation on orthosteric ligand binding. The $\mathrm{K}_{\mathrm{B}}$ and $\alpha$ values of the synthesized compounds are presented in Table 1. In comparison with their indole- 2-carboxamide counterparts $3 \mathrm{a}$ and $3 \mathrm{~b}$, the 7 -azaindole2-carboxamides $9 \mathrm{a}$ and $9 \mathrm{~b}$ completely lost their binding affinity to the $\mathrm{CB}_{1}$ receptor, likely influenced by the poor solubility of these compounds. In contrast, the 6-azaindole-2-carboxamides $3 \mathrm{c}$ and $3 \mathrm{~d}$ exhibited modest binding affinity to the $\mathrm{CB}_{1}$ receptor. Interestingly, 6 azaindole-2-carboxamide $3 \mathrm{~d}$ showed comparable allosteric modulation on the binding of orthosteric agonist $\mathrm{CP55}, 940$, while its binding to the $\mathrm{CB}_{1}$ receptor was reduced by about 25 -fold in comparison with its indole-2carboxamide counterpart $3 \mathrm{~b}$. These results from $9 \mathrm{a}$ and $9 \mathrm{~b}$ suggested that the 7-azaindole is not an optimal bioisostere for replacing the indole ring in the class of $\mathrm{CB}_{1}$ allosteric modulators, although it has been successfully used as an effective bioisostere in other indole-containing bioactive molecules. ${ }^{14}$

Table 1. Binding Parameters for the Synthesized Compounds

\begin{tabular}{|c|c|c|c|c|}
\hline Entry & Compd Code & Structure & $K_{B}(\mu M)^{a}$ & $\alpha^{\mathbf{b}}$ \\
\hline $3 a$ & LDK1322 & & 0.3 & 4.2 \\
\hline $3 b$ & LDK1326 & & 0.2 & 5.1 \\
\hline $3 c$ & LDK1314 & & 2.4 & 3.2 \\
\hline $3 d$ & LDK1316 & & 5.6 & 4.4 \\
\hline $9 a$ & LDK1313 & & $N B^{c}$ & $N A^{d}$ \\
\hline $9 b$ & LDK1315 & & $N B^{c}$ & $N A^{d}$ \\
\hline
\end{tabular}

\footnotetext{
The red color indicates that the $\mathrm{N}$ is the newly introduced nitrogen on the original indole ring.

${ }^{\mathrm{a}} \mathrm{K}_{\mathrm{B}}$ : equilibrium dissociation constant.

$\mathrm{b}_{\alpha \text { : binding cooperativity factor. }}$

'NB: no detectable modulation.

${ }^{\mathrm{d} N A}$ : not applicable.
} 


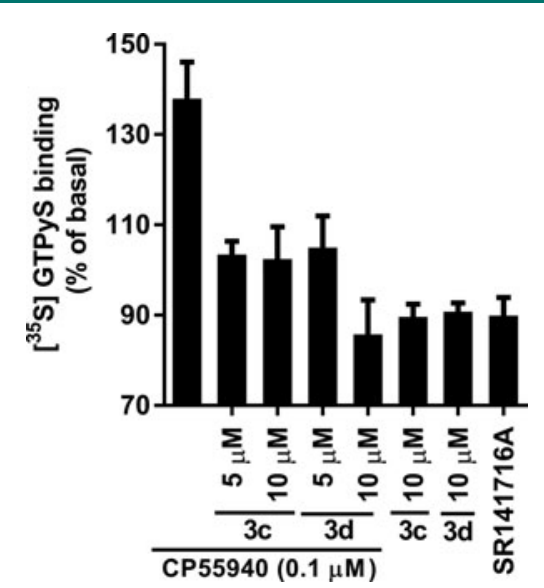

FIG. 3. Response of $3 c$ (LDK1314) and $3 d$ (LDK1316) on $\left[{ }^{35} \mathrm{~S}\right] \mathrm{GTP} \gamma \mathrm{S}$ binding to membranes expressing $\mathrm{CB}_{1}$. The effects of $0.1 \mu \mathrm{M} C \mathrm{CP} 5,940$

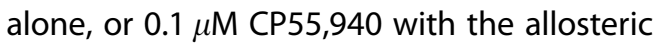
modulators $3 c$ or $3 \mathrm{~d}, 3 \mathrm{c}$, or $3 \mathrm{~d}$ alone, or $1.0 \mu \mathrm{M}$ SR141716A alone on $\left.{ }^{35} \mathrm{~S}\right] \mathrm{GTP} \gamma \mathrm{S}$ binding were measured at the concentrations indicated. Data are presented as a percentage of basal levels of $\left[{ }^{35} \mathrm{~S}\right] \mathrm{GTP} \gamma \mathrm{S}$ binding. Nonspecific binding was measured in the presence of $10 \mu \mathrm{M}$ unlabeled GTP $\gamma$ S. Each data point represents the mean \pm standard error of the mean of at least three independent experiments performed in duplicate. GTP $\gamma \mathrm{S}$, guanosine 5'-O-[gammathio]triphosphate.

To investigate G-protein coupling induced by the allosteric modulators, the 6-azaindole-2-carboxamides $3 \mathrm{c}$ and $3 \mathrm{~d}$ were tested for their impact on GTP $\gamma \mathrm{S}$ binding. These results, plotted as percent of basal levels of $\mathrm{CB}_{1} \mathrm{ac}-$ tivity, are shown in Figure 3. Both $3 \mathrm{c}$ and $3 \mathrm{~d}$ showed an inhibition of GTP $\gamma \mathrm{S}$ binding at 5 and $10 \mu \mathrm{M}$ in the presence of $0.1 \mu \mathrm{M}$ CP55,940, compared to membranes treated with $0.1 \mu \mathrm{M}$ of CP55,940 alone. These data suggest that although the allosteric modulators apparently enhanced the binding of CP55,940, the G-protein coupling induced by CP55,940 was inhibited. In addition, inhibition of G-protein coupling was also seen when $\mathrm{CB}_{1}$ was treated with $3 \mathrm{c}$ and $3 \mathrm{~d}$ alone. The level of G-protein coupling inhibition achievable is comparable to that observed with the inverse agonist SR141716A, although the orthosteric compound SR141716A and the allosteric modulators, $3 \mathrm{c}$ and $3 \mathrm{~d}$, likely inhibit G-protein coupling via different mechanisms.
Table 2. Calculated Aqueous Solubility and the Experimental Thermodynamic Solubility of Compounds $3 a, 3 c$, and $9 a$

\begin{tabular}{|c|c|c|}
\hline Compound & Aqueous solubility ${ }^{a}$ & Thermodynamic solubility $^{b}$ \\
\hline 3а & $3.0 \mu \mathrm{g} / \mathrm{mL}$ & $0 \mu \mathrm{g} / \mathrm{mL}$ \\
\hline $3 c$ & $8.0 \mu \mathrm{g} / \mathrm{mL}$ & $1.6 \mu \mathrm{g} / \mathrm{mL}$ \\
\hline $9 a$ & $6.0 \mu \mathrm{g} / \mathrm{mL}$ & $3.0 \mu \mathrm{g} / \mathrm{mL}$ \\
\hline
\end{tabular}

In the solubility tests, we selected compounds $3 c, 3 d$, and 9a because they represented the indole, 6 -azaindole and 7-azaindole scaffold, respectively. We found that compound 9a has exceptionally low solubility in common organic solvents suitable for HPLC sample preparation such as methanol, acetone, and their mixtures with different stoichiometry. We tried the sampling method reported previously to prepare stock solution of $9 \mathrm{~d}$ into a $2 \%-5 \%$ DMSO in Acetonitrile solution. ${ }^{22}$ Addition of aqueous PBS media led to precipitation of the compound. This made us unable to determine the standard curve for analysis of 9d. Hence, only compounds $3 \mathrm{c}$ and $3 \mathrm{~d}$ were analyzed. The individual solubility of $3 c, 3 d$, and $9 \mathrm{a}$ was also simulated using a program (Chemicalize). The simulated aqueous solubility of these three compounds was reported along with the experimental solubility of $3 \mathrm{c}, 3 \mathrm{~d}$, and $9 \mathrm{a}$ in Table 2 .

The results from solubility studies showed that using 6- and 7-azaindole in lieu of the indole moiety led to enhancement of aqueous solubility compared to the indole counterpart although their solubility are still poor and far below optimal solubility. This finding is in agreement with the results in an early investigation, of which 6- and 7-azaindole analogs showed solubility enhancement in comparison with indole counterpart. ${ }^{16}$ The binding parameters of the synthesized compounds suggested that the 6-azaindole scaffold is worth further exploration, whereas the 7 -azaindole ring is not a viable bioisostere of the indole ring in the Org27569 class of $\mathrm{CB}_{1}$ allosteric modulators.

Although their binding affinity for $\mathrm{CB}_{1}$ was less than their indole-2-carboxamide counterparts, they showed similar coupling characteristics as Org27569, in which they decreased G-protein coupling when compared with treatment with CP55,940 alone, indicating that they may induce signaling in a way similar to Org27569 and its analogs. Further research is needed to fully elucidate the signaling pathways of these compounds; however, it might involve beta-arrestin coupling and signaling such as Org27569 and its previously tested analogs. ${ }^{20,27,28} \mathrm{We}$ 
